\title{
Tool use by Choerodon cyanodus when handling vertebrate prey
}
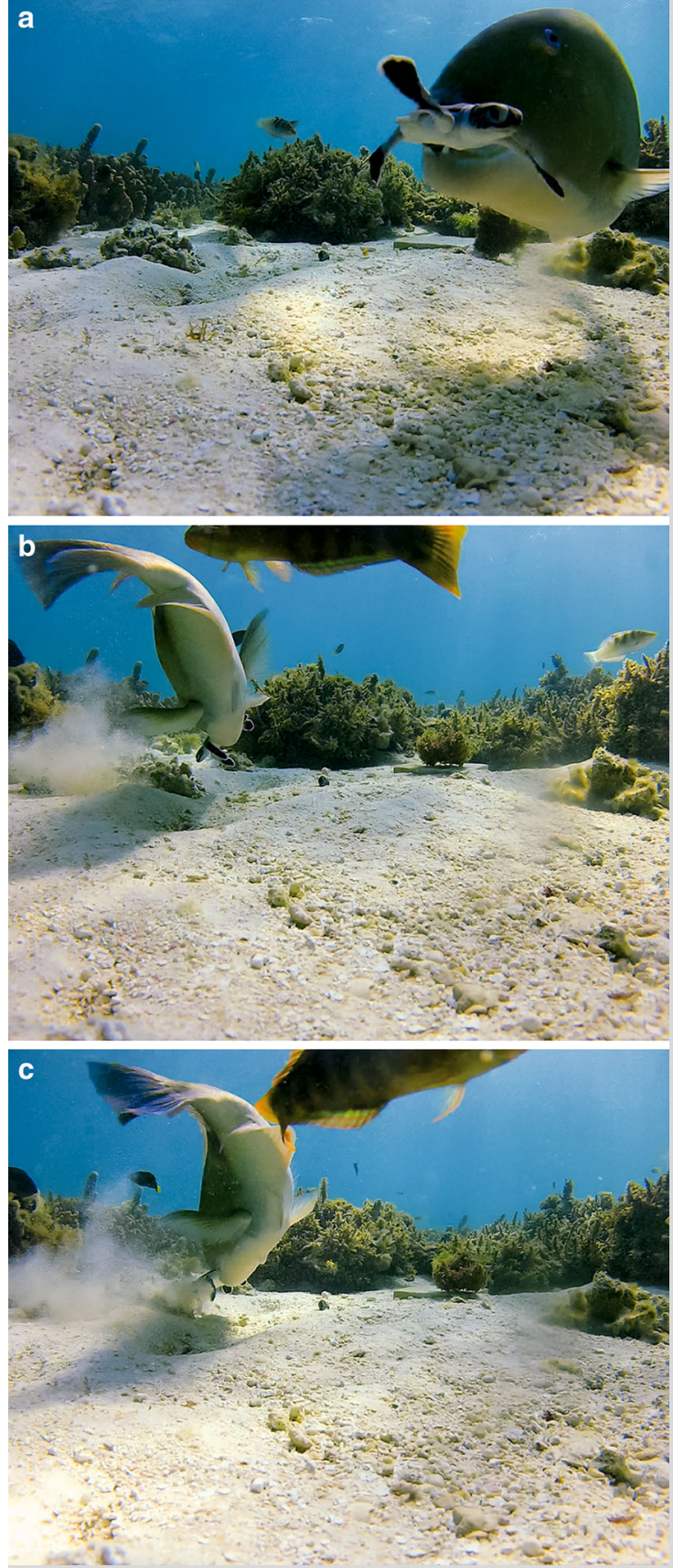

Fig. 1 a-c Sequence of photographs showing Choerodon cyanodus a entering the frame with a live, juvenile Chelonia mydas, b, c striking the turtle against a rock
The use of an anvil during prey handling fulfils the criteria of tool use and can be considered a sign of intelligence (Jones et al. 2011). Tool use has only recently been described for fishes and is currently limited to wrasses handling invertebrate prey (e.g., breaking open cockles and bivalves; Jones et al. 2011; Bernardi 2012). Here, we extend this behaviour to a further tuskfish species and provide the first documentation of this behaviour for a vertebrate prey item.

On 13 February 2014, at $\sim 0850 \mathrm{~h}$ a remotely deployed video camera serendipitously filmed an adult blue tuskfish (Choerodon cyanodus) with a juvenile green turtle (Chelonia mydas) in its mouth on the shallow $(<2 \mathrm{~m})$ outer reef flat around Heron Island, Great Barrier Reef, Australia. Choerodon cyanodus has previously been documented as a major predator of turtles on this reef (Gyuris 1994), but how the tuskfish handles this prey item has not been recorded. Our 23-s sequence shows the tuskfish repeatedly using a small rock as an anvil while in both sideways and head-down body positions (Fig. 1; Electronic Supplementary Material). The tuskfish also uses a larger, dead coral formation as a second anvil for additional strikes. The blows either stun or kill the turtle as flipper movement seen at the start of the sequence is no longer visible when the fish exits the frame.

It is unknown whether the use of the anvil was just to incapacitate the turtle to aid prey handling or whether it also functioned to break open the carapace to help with swallowing and digestion. However, this behaviour shows that tool use may indeed be particularly common in the ancestral Choerodon genus and potentially a deep-seated behavioural trait in wrasses (Bernardi 2012), and used for a wider range of prey items than previously known. Whether this behaviour extends to other groups of fishes, allowing them to eat prey items larger than their gape size, remains a tantalising question.

Acknowledgments ARH was funded by Australian Research Council fellowship DE120102459. We thank C. Cordeiro and M. Priest.

\section{References}

Bernardi G (2012) The use of tools by wrasses (Labridae). Coral Reefs 31:39 Gyuris E (1994) The rate of predation by fishes on hatchlings of the green turtle (Chelonia mydas). Coral Reefs 13:137-144

Jones AM, Brown C, Gardner S (2011) Tool use in the tuskfish Choerodon schoenleinii? Coral Reefs 30:865

Electronic supplementary material The online version of this article (doi:10.1007/s00338-016-1448-6) contains supplementary material, which is available to authorized users.

A. R. Harborne $(\bowtie) \cdot$ B. A. Tholan

School of Biological Sciences, Goddard Building, The University of Queensland, Brisbane, QLD 4072, Australia

e-mail: a.harborne@uq.edu.au 